Int. J. Curr. Res. Med. Sci. (2017). 3(5): 14-20

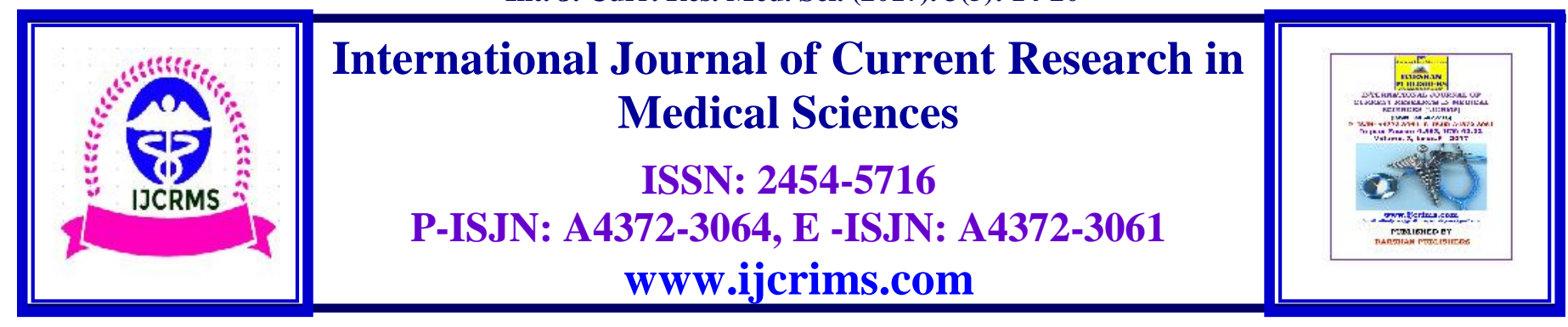

\title{
Clinical Profile and Aids to Diagnosis and Management of Trauma Abdomen
}

\author{
*Bhupinder Singh Walia,**Venita Kapur,***TabangNyitan,**Kiranjot, \\ ***Rahul Singh, $* * * *$ N.S.Neki \\ *Assistant Professor,**Professor,***Junior Resident, Department of Surgery, Govt. Medical College/ Guru \\ Nanak Dev Hospital, Amritsar, India, 143001 \\ *****Professor of Medicine, Govt. Medical College, Amritsar, India \\ Corresponding Author: Dr. Bhupinder Singh Walia, Assistant Professor, Department of Surgery, \\ Govt. Medical College/ Guru Nanak Dev Hospital, Amritsar, India, 143001 \\ E-mail: bhupindersinghwalia6@gmail.com
}

\begin{abstract}
Abdominal trauma, both blunt and sharp, is a major public problem and constitutes one of the serious and major surgical emergencies for surgeons worldwide. Frequently, more obvious multiple injuries to head, thorax and extremities may mask the blunt abdominal trauma. A better understanding of the etiology and pattern of such injuries can help to improve the management and outcome of these patients. Blunt trauma abdomen is more common in males in age group of 21-30 years and majority of injuries are due to road traffic accidents. Solid organs of upper abdomen such as spleen and liver are primarily injuried in blunt trauma abdomen. In penetrating injuries small intestine is most frequently injuried. About $15 \%$ of all pelvic fractures are associated with concomitant bladder and urethral injuries. A direct blow to lower abdomen may result in bladder disruption; mainly intra peritoneal. This study was done to determine the incidence of trauma abdomen and its various parameters like age, sex, mode of injury, its radiological findings and detail of visceral injuries and patients' outcome.
\end{abstract}

Keywords: abdominal trauma, incidence, outcome.

\section{Introduction}

The abdomen is the third most common injured region, with surgery required in about $25 \%$ of civilian cases ${ }^{1}$. Abdominal trauma is traditionally classified as either blunt or penetrating. Penetrating abdominal trauma can usually be diagnosed easily and reliably, whereas blunt abdominal trauma is often missed because clinical signs are less obvious ${ }^{2}$. Blunt abdominal injuries predominate in rural areas, while penetrating ones are more frequent in urban settings ${ }^{1}$. Penetrating abdominal trauma is often subdivided into stab wounds and gunshot wounds, which require different methods of treatment ${ }^{3}$. Penetrating injuries from gunshot are obvious and high velocity missiles producing cavitations within the abdomen is sufficient to disrupt hollow organs ${ }^{4}$. Blunt abdominal trauma is more common in males of younger age group and majority of 
injuries are due to automobile accidents ${ }^{5}$. Solid organs of upper abdomen such as spleen and liver are primarily injured in blunt abdominal trauma. In penetrating injuries, small bowel ism most frequently injured, however incidence of small bowel injuries in blunt abdominal trauma is $5 \%$ to $20 \%$.

The key to successful diagnosis of trauma abdomen are high index of suspicion, frequent physical examination and close observation added with diagnostic evaluation. To decide which abdomen should be explored surgically, a thorough physical examination and diagnostic study is required with signs of peritoneal penetration, unexplained shock and free gas under the domes of diaphragm on X-ray chest.

\section{Materials and Methods}

We studied a total of 50 cases admitted to Guru Nanak Dev Hospital/ Govt. Medical College, Amritsar (Punjab) with provisional diagnosis of abdominal trauma.

The record of these patients were analyzed with respect to nature of injury (either blunt or sharp), site of injury, associated injuries, clinical signs and symptoms, various investigations (plain Xray chest, plain X-ray abdomen, ultrasonography, abdominal paracentesis), surgery performed, organ injured, morbidity and mortality.

\section{Results}

In our study of 50 patients, $80 \%$ patients $(\mathrm{n}=40)$ had blunt abdominal trauma and 20\% $(\mathrm{n}=10)$ had penetrating trauma abdomen. Age of patients ranged from 5 years to 75 years but most of cases were between 21 years to 30 years. Male patients were $84 \%(n=42)$ while $16 \%$ patients $(n=8)$ were female. In these patients, the most common mode of injury was road side accident with 54\% patients $(\mathrm{n}=27)$, followed by $20 \%$ patients $(\mathrm{n}=10)$ due to assault of different natures, $14 \%$ patients $(n=7)$ due to fall from height, 6\% patients $(n=3)$ due to hits from animals and $2 \%$ patients $(\mathrm{n}=1)$ each due to gun shot injuries, objects falling on abdomen and railway accidents (figure 1). 22 patients $(44 \%)$ presented with pulse rate $<100 /$ min and $28(56 \%)$ patients presented with pulse rate $>100 /$ min (Table 1).

\section{Figure 1. Mode of injury}

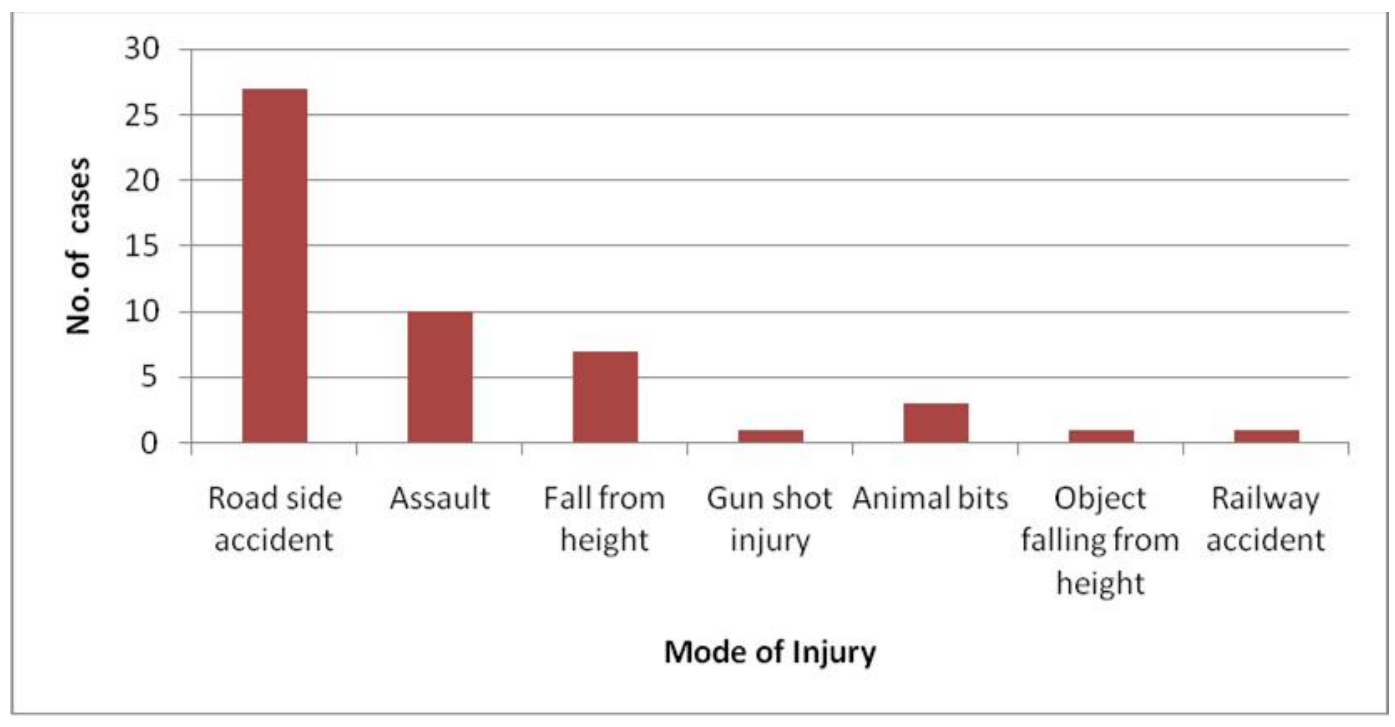


Int. J. Curr. Res. Med. Sci. (2017). 3(5): 14-20

Table 1. Pulse at the time of admission

\begin{tabular}{|l|c|c|}
\hline \multirow{2}{*}{ Pulse rate } & \multicolumn{2}{|c|}{ Patients } \\
\cline { 2 - 3 } & Numbers & Percentage \\
\hline$<100$ & 22 & 44 \\
\hline $101-120$ & 19 & 38 \\
\hline $121-140$ & 8 & 16 \\
\hline$>140$ & 1 & 2 \\
\hline
\end{tabular}

The observations of blood pressure at the time of admission shows systolic blood pressure below 90 $\mathrm{mm} \mathrm{Hg}$ in $6 \%$ of the cases and 90 to $140 \mathrm{~mm}$ in
$90 \%$ of cases and above $140 \mathrm{~mm}$ in $4 \%$ of cases (Figure 2).

Figure 2. Blood pressure at the time of admission

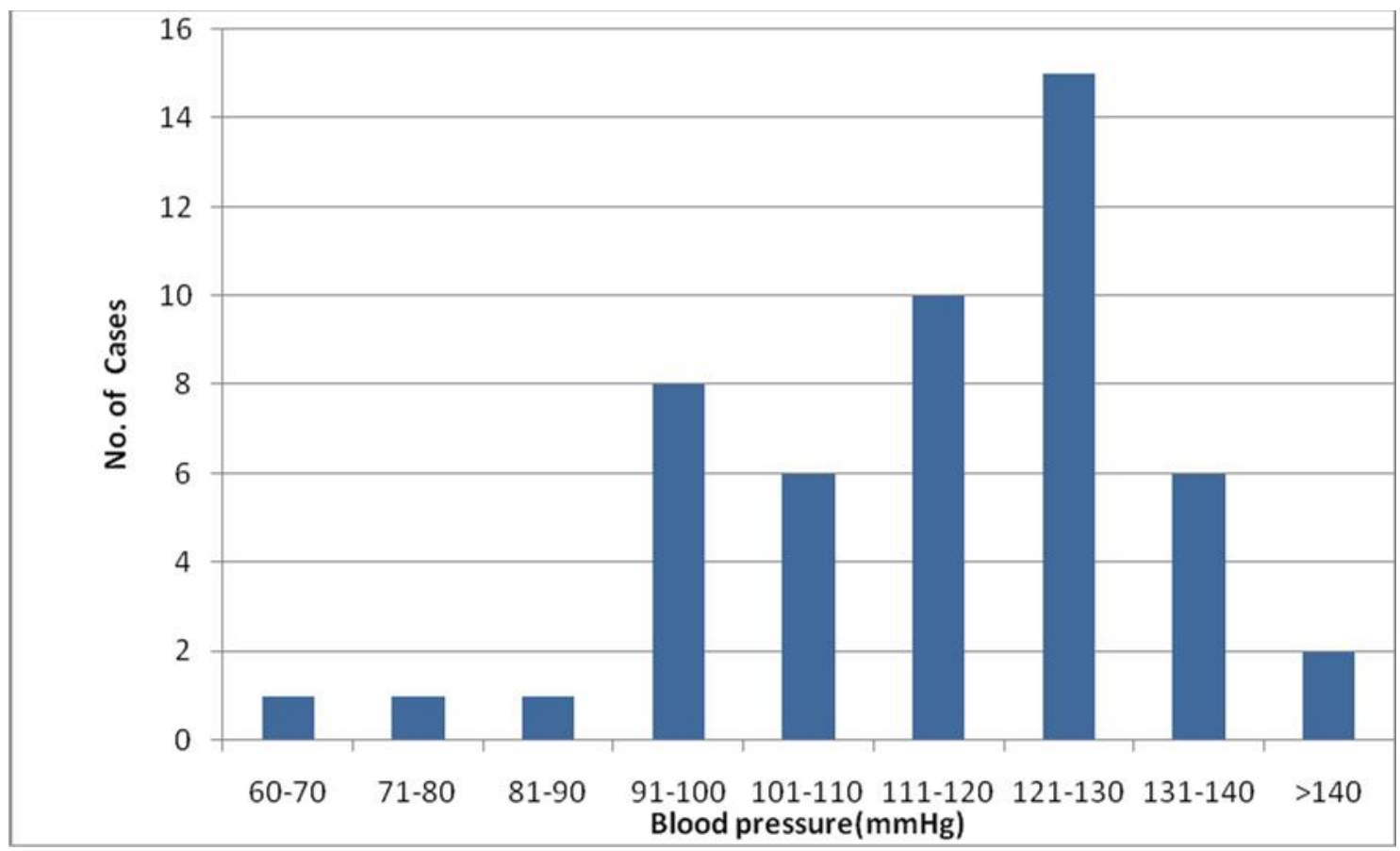

The clinical symptoms of pain abdomen were seen in 48 patients and vomiting in 14 patients. Clinical signs of abdominal tenderness were observed in 44 patients, guarding and rigidity in 27 patients and distension of abdomen in 13 patients, bowel sound was positive in 34 patients, 11 patients had signs of dehydration and 3 patients presented with shock.
Haemoglobin at the time of admission was estimated in $57 \% \quad(n=15)$ patients out of 26 patients with proved visceral injuries and had haemoglobin $10 \mathrm{gm} \%$ or below $10 \mathrm{gm} \%$.

The radiological studies showed air under diaphragm in $20 \%$ cases $(n=10)$ and dilated gut loop in $2 \%(n=1)$ besides other findings as shown in table 2. 
Int. J. Curr. Res. Med. Sci. (2017). 3(5): 14-20

Table 2. Radiological study

\begin{tabular}{|l|c|c|}
\hline \multirow{2}{*}{$\begin{array}{c}\text { Findings on X-ray chest } \\
\text { (PA view) and plain X-ray } \\
\text { abdomen (with both domes } \\
\text { of diaphragm) }\end{array}$} & \multicolumn{2}{|c|}{ Patients } \\
\cline { 2 - 3 } & Number & Percentage \\
\hline Air under diaphragm & 10 & 20 \\
\hline Dilated gut loops & 1 & 2 \\
\hline Fracture of ribs & 4 & 8 \\
\hline Fracture of pelvic bones & 1 & 2 \\
\hline $\begin{array}{l}\text { Displacement of gastric } \\
\text { shadow }\end{array}$ & 1 & 2 \\
\hline Pleural effusion & 2 & 4 \\
\hline No abnormality detected & 31 & 62 \\
\hline
\end{tabular}

Ultrasonographic findings in our study revealed free fluid in peritoneal cavity in $23 \%$ patients $(\mathrm{n}=11)$, dilated gut loops in $4 \%$ patients $(\mathrm{n}=2)$, collections around spleen/splenic injuries in 10\% patients $(\mathrm{n}=5)$, pleural effusion in $6 \%$ patients $(\mathrm{n}=3)$, liver injuries in $4 \%$ patients $(\mathrm{n}=2)$ and renal injuries in $4 \%$ patients $(\mathrm{n}=2)$.
Associated injuries along with trauma abdomen were head injury in $20 \%$ patients $(n=10)$, multiple injuries in $12 \%$ patients $(\mathrm{n}=6)$, extremities fractures in $10 \%$ patients $(\mathrm{n}=5)$, chest/ribs injuries in $8 \%$ patients $(\mathrm{n}=4)$, pelvic injuries in $6 \%$ patients $(\mathrm{n}=3)$ and spinal injuries in $6 \%$ patients $(n=3)$ as shown in the figure 3 .

Diagnostic abdominal paracentesis was done in 22 cases out of 50 cases. In 16 cases it was blood and in 6 cases it was feculent fluid.

Figure 3. Associated injuries in trauma abdomen

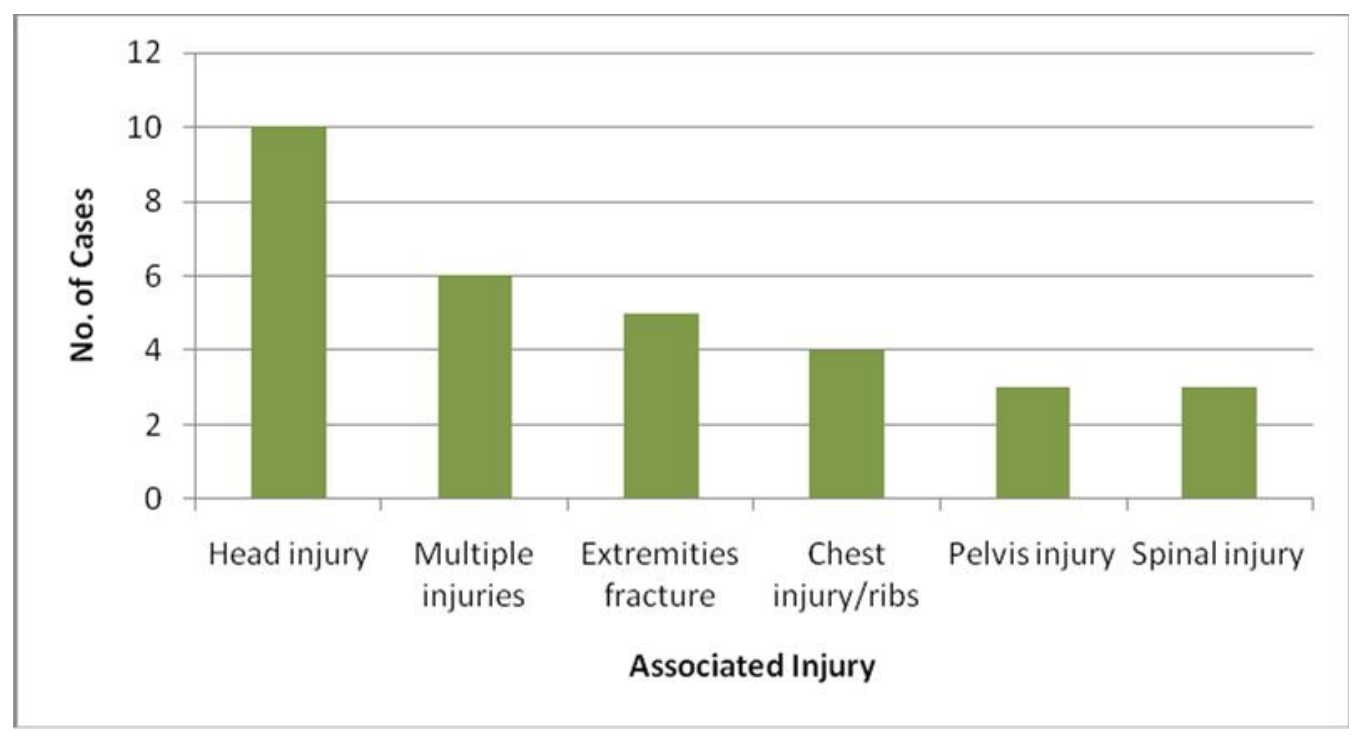

Explorative laparotomy was done in 26 cases and 22 patients were treated conservatively in our study. Two patients with local injuries of abdomen were stitched locally. Visceral injuries in 26 patients who underwent explorative laparotomy are shown in table 3 .
Post operative complications were seen in 9 patients out of total 28 patients who were operated and their details are given in table 4 . 
Int. J. Curr. Res. Med. Sci. (2017). 3(5): 14-20

Table 3. Visceral organ injury

\begin{tabular}{|l|c|c|}
\hline \multirow{2}{*}{\multicolumn{1}{|c|}{ Organ injured }} & \multicolumn{2}{|c|}{ Patients } \\
\cline { 2 - 3 } & Number & Percentage \\
\hline Spleen & 7 & 14 \\
\hline Liver & 5 & 10 \\
\hline Ileum & 6 & 12 \\
\hline Colon & 5 & 10 \\
\hline Kidney & 2 & 4 \\
\hline Urinary bladder & 1 & 2 \\
\hline
\end{tabular}

Table 4. Postoperative complications

\begin{tabular}{|l|c|c|}
\hline \multirow{2}{*}{\multicolumn{1}{|c|}{ Complications }} & \multicolumn{2}{|c|}{ Patients } \\
\cline { 2 - 3 } & Number & Percentage \\
\hline Wound infection & 4 & 14.28 \\
\hline Pleural effusion & 3 & 10.71 \\
\hline Partial wound dehiscence & 1 & 3.57 \\
\hline Hyperpyrexia & 1 & 3.57 \\
\hline
\end{tabular}

\section{Discussion}

In this study, blunt abdominal trauma constituted $80 \%$ of cases and penetrating abdominal injuries $20 \%$ of cases. Consistent with our results, previous studies found that most abdominal injuries were caused by blunt trauma ${ }^{7}$.

In our study, the most common age in abdominal trauma among males is third decade (between 2130 years) and male predominance is $84 \%$ which is consistent with Lone et al.'s report of a male to female ratio of 4.4: 1 among abdominal trauma patients ${ }^{8}$. Young males, mostly those aged 20 to 30 years, have been reported to be the most frequent victims ${ }^{9}$. It is also comparable to the study by Gupta et $\mathrm{al}^{4}$. In a study on hospitalized trauma patients at the Poursina teaching hospital, most of the patients were in the age range $20-44$ years and the ratio of trauma affected men was 3.6 times more than women ${ }^{10}$. Similar results were shown by Mohammed A Gad et $\mathrm{al}^{11}$. In a study by Ahmadi et al., most of the chest traumatic patients were adult men with a mean age of 35 years old and mode of 30, and road accidents were the most prevalent cause of trauma $^{12}$.

Majority of patients in this study, had injuries due to road side accidents which constituted 54\% cases, the possible reasons for such a high percentage of road side accident in our part of country were ignorance of traffic rules, poor driving skills, drunken driving, poor road engineering and growing commercial activity along important roads. Vehicle accidents are a common cause of blunt abdominal trauma ${ }^{1}$. The second most common cause of injury was assault following fall from height. Gad et al. reported that most of the abdominal trauma patients were men and motor vehicle accidents were the main cause of abdominal trauma followed by falling or assault in second place ${ }^{13}$.

Majority of patient in our study presented with tachycardia with blood pressure below $90 \mathrm{~mm} \mathrm{Hg}$ (systolic) which is comparable to the study conducted by Foley et $\mathrm{al}^{14}$.

Clinical signs and symptoms findings in our study i.e. pain abdomen in 48 (96\%) patients, abdominal tenderness in 44 (88\%) patients, guarding and rigidity in $27(54 \%)$ patients, abdominal distension in $13(26 \%)$ patients and shock in $3(6 \%)$ patients was comparable to the findings of the study conducted by Frega GP et $\mathrm{al}^{15}$.

Haemoglobin estimation at the time of admission in our study showed a level of $10 \mathrm{gm} \%$ or below in 15 patients out of 26 patients with proved visceral injuries which indicate intraabdominal haemorrhage. 
In plain $x$ ray chest with both domes of diaphragm, air under diaphragm was the most common presentation in $10(20 \%)$ patients. Ultrasonography, very sensitive investigation in detection of fluid in peritioneal cavity, showed free fluid in peritoneal cavity in 11 patients(22\%) which is comparable to the study conducted by Rothelin MA et al ${ }^{16}$.

Abdominal paracentesis (four quadrants aspiration) was done in 22 patients out of 50 patients. Accuracy of paracentesis was $82 \%$ in this study which is comparable to the study conducted by Nehef and Cohen ${ }^{17}$.

The analysis of associated injuries in our study showed that most common presentation of patient was road side accidents with head injury $20 \%$, chest injuries $8 \%$, pelvic injuries $6 \%$ and spinal injuries $6 \%$ which is comparable to the study conducted by McLellan et $\mathrm{al}^{18}$.

In management of the patients in present study explorative laparotomy was done in 26 patients and 22 were managed conservatively. In explorative laparotomy, perforations of gut in 9 cases were repaired in double layers with vicryl 20 and silk 2-0 and resection anastomosis in 13 cases was done where gut segment was gangrenous.

The other injuries seen were splenic injuries in $14 \%$ cases, liver injuries in $10 \%$ cases, kidney injuries in $4 \%$ cases, ileal injuries in $12 \%$ cases and colon injuries in $10 \%$ cases. In patients with penetrating abdominal lesions, the most common were liver and spleen damage. Similar results were described by Smith et al. and Isenhour et $\mathrm{al}^{19,20}$. According to a study by Godbole and Stringer, most internal damage of the abdomen occurred in the spleen ${ }^{21}$.

The most occured complication of laparotomy in our study was wound infection seen in 4 patients. The other complications observed were pleural effusions in 3 patients, partial dehiscence of wound in 1 case and hyperpyrexia in 1 case. These complications were managed accordingly and the patients recovered from these complications.
Out of 26 patients who were operated upon in present study:

the outcome of the patients was:

* Cured - 24 patients

*Expired - 2 patients ( had multiple organ failure)

22 patients were conservatively managed and outcome in these patients was :

*Cured - 21 patients

*Expired - 1 patient (had extensive head injury)

\section{Conclusion}

Road traffic accidents form the most common mode of trauma abdomen and blunt trauma is more common in young males mostly in third decade .Spleen and liver among solid and small gut among hollow organs are most commonly injuried. In this study it was concluded that operative procedure was necessary in a large number of cases and if required early operation decreases the mortality in blunt trauma abdomen especially in unstable patients. The patient outcome is good if appropriate diagnosis and management is done early and accurately.

\section{Source of funding: Nil}

Conflict of interest: None declared.

\section{References}

1. Hemmila MR, Wahl WL. Management of the Injured Patient. In: Doherty GM, editor. Current Surgical Diagnosis and Treatment. McGraw-Hill Medical; 2008. pp. 227-8.

2. Aldemir M, Tacyildiz I, Girgin S. Predicting factors for mortality in the penetrating abdominal trauma. Acta Chir Belg. 2004;104:429-34.

3. Jansen JO, Yule SR, Loudon MA. Investigation of blunt abdominal trauma. BMJ. 2008;336:938-42.

4. Gupta S. Talwar S, Sharma RK, Gupta P, Goyal A, Prasad P. Blunt trauma abdomen: A study of 63 cases. Ind J Med Sciences 1996; 50(8): 272-276. 
5. Aron J. A study of hepatic injuries. Am J Surg 1996; 63: 908-916.

6. Sabiston. Management of acute trauma. In: Sabiston Textbook of Surgery, 18th Ed., Ch. 20; pp. 507-508.

7. Smith J, Caldwell E, D’Amours S, Jalaludin B, Sugrue M. Abdominal trauma: A disease in evolution. ANZ J Surg. 2005;75:790-4.

8. Lone GN, Peer GQ, Warn AK, Bhat AM, Warn NA. An experience with abdominal trauma in adults in Kashmir. JK Pract. 2001;8:225-30.

9. Baradaran H, Salimi J, Nassaji-Zavareh M, Khaji A, Rabbani A. Epidemiological study of patients with penetrating abdominal trauma in Tehran-Iran. Acta Med Iran. 2007;45:305-8.

10. Yousefzadeh S, Ahmadi Dafchahi M, Mohammadi Maleksari M, Dehnadi Moghadam A, Hemati H, Shabani S. [Epidemiology of Injuries and their Causes among TraumaticPatients Admitted into Poursina Hospital,Rasht (second half of the year 2005)]. Behboud.2007;11(34):286-95. 11.

11. Mohammed A Gad, Aly Saser. Incidence, pattern \& factors predicting mortality of abdominal injuries in trauma patients. $\mathrm{N} \mathrm{Am} \mathrm{J}$ Sci 2012 Mar; 4(3): 129-134.

12. Ahmadi Amoli H, Zafarghandi MR, Tavakoli H, Davoodi M, Khashayar P. Thoracic Trauma: Severity of Injury in 342 Patients. TUMJ.2009;66(11):831

13. Gad MA, Saber A, Farrag S, Shams ME, Ellabban GM. Incidence, patterns, and factors predicting mortality of abdominal injuries in trauma patients. N Am J Med Sci.2012;4(3):129-34.

14. Foley RW, Harris LS, Pilcher DB. Abdominal injuries in automobile accidents: Review of care of fatally injured patients. J Trauma 1977; 17: 611.

15. Frega GP, Silva FH, Almeida NA, Curie JC, Mantovani M. Blunt abdominal trauma with small bowel injury are isolate lesions riskier than associated lesions. Acta Cir Bras 2008; 23: 102-110.

16. Rothelin MA, Naf R, Amgwerd M, Candians $\mathrm{D}$, Frick T, Trentz O. Ultrasound in blunt abdominal and thoracic trauma. J Trauma 1991; 34(4): 488-492.

17. Nehof and Kohen. Abdominal puncture in diagnosis of acute abdominal diseases. Annal Surg 1926; 83: 454.

18. Mclellan HA, Hanna SS, Montoya R, Harrison AW, Taylor A, Miller HA, et al. Analysis of peritoneal lavage parameters in blunt abdominal trauma. J Trauma 1985; 25(5): 393-394

19.Isenhour JL, Marx J. Advances in abdominal trauma. Emerg Med Clin North Am.2007;25(3):713-33, ix.

20. 11. Smith J, Caldwell E, D'Amours S, Jalaludin B, Sugrue M. Abdominal trauma: a disease in evolution. ANZ J Surg.2005;75(9):790-4.

21. Godbole P, Stringer MD. Splenectomy after paediatric trauma: could more spleens be saved? Ann R Coll Surg Engl.2002; 84(2): 106-8.

\begin{tabular}{|c|l|}
\hline \multicolumn{2}{|c|}{ Access this Article in Online } \\
\hline Quick Response Code & Website: \\
& Www.ijcrims.com \\
\hline Qubject: \\
\hline
\end{tabular}

How to cite this article:

Bhupinder Singh Walia, Venita Kapur, TabangNyitan, Kiranjot, Rahul Singh, N.S.Neki (2017). Clinical Profile and Aids to Diagnosis and Management of Trauma Abdomen. Int. J. Curr. Res. Med. Sci. 3(5): 14-20.

DOI: http://dx.doi.org/10.22192/ijcrms.2017.03.05.004 